\title{
Cytogenetic map of common bean (Phaseolus vulgaris L.)
}

\author{
Artur Fonsêca • Joana Ferreira • Tiago Ribeiro Barros dos Santos • \\ Magdalena Mosiolek • Elisa Bellucci • James Kami • Paul Gepts • \\ Valérie Geffroy • Dieter Schweizer • Karla G. B. dos Santos • \\ Andrea Pedrosa-Harand
}

Received: 28 January 2010 /Revised: 12 March 2010/Accepted: 28 March 2010 /Published online: 7 May 2010

(C) The Author(s) 2010. This article is published with open access at Springerlink.com

\begin{abstract}
A cytogenetic map of common bean was built by in situ hybridization of 35 bacterial artificial chromosomes (BACs) selected with markers mapping to eight linkage groups, plus two plasmids for $5 \mathrm{~S}$ and 45S ribosomal DNA and one bacteriophage. Together with three previously mapped chromosomes (chromosomes 3, 4, and 7), 43 anchoring points between the genetic map and the cytogenetic map of the species are
\end{abstract}

Responsible Editor: Hans de Jong.

Electronic supplementary material The online version of this article (doi:10.1007/s10577-010-9129-8) contains supplementary material, which is available to authorized users.

A. Fonsêca · J. Ferreira • T. R. B. dos Santos ·

K. G. B. dos Santos $\cdot$ A. Pedrosa-Harand

Laboratory of Plant Cytogenetics, Department of Botany,

Federal University of Pernambuco,

Recife, PE 50670-420, Brazil

M. Mosiolek $\cdot$ D. Schweizer $\cdot$ A. Pedrosa-Harand $(\square)$

Department of Chromosome Biology,

University of Vienna,

1030 Vienna, Austria

e-mail: andrea.pedrosaharand@pesquisador.cnpq.br

M. Mosiolek $\cdot$ D. Schweizer

Gregor Mendel Institute of Molecular Plant Biology,

Austrian Academy of Sciences,

1030 Vienna, Austria

E. Bellucci

Dipartimento di Scienze Ambientali e delle Produzioni

Vegetali, Università Politecnica delle Marche,

60131 Ancona, Italy now available. Furthermore, a subset of four BAC clones was proposed to identify the 11 chromosome pairs of the standard cultivar BAT93. Three of these BACs labelled more than a single chromosome pair, indicating the presence of repetitive DNA in their inserts. A repetitive distribution pattern was observed for most of the BACs; for $38 \%$ of them, highly repetitive pericentromeric or subtelomeric signals were

E. Bellucci

National Institute of Agricultural Botany,

Cambridge CB3 0LE, UK

J. Kami $\cdot$ P. Gepts

Department of Plant Sciences/MS1,

Section of Crop and Ecosystem Sciences,

University of California,

Davis, CA 95616-8780, USA

V. Geffroy

Institut de Biotechnologie des Plantes, UMR-CNRS 8618,

INRA, Université Paris Sud,

91405 Orsay, France

V. Geffroy

Unité Mixte de Recherche de Génétique Végétale, Institut National de la Recherche Agronomique, 91190 Gif-sur-Yvette, France 
observed. These distribution patterns corresponded to pericentromeric and subtelomeric heterochromatin blocks observed with other staining methods. Altogether, the results indicate that around half of the common bean genome is heterochromatic and that genes and repetitive sequences are intermingled in the euchromatin and heterochromatin of the species.

Keywords fluorescent in situ hybridization (FISH) . bacterial artificial chromosome (BAC) - physical map . repetitive DNA sequences $\cdot$ Fabaceae

$\begin{array}{ll}\text { Abbreviations } \\ \text { BAC } & \text { Bacterial artificial chromosome } \\ \text { CMA } & \text { Chromomycin A3 } \\ \text { DAPI } & \text { 4',6-diamidino-2-phenylindole } \\ \text { FISH } & \text { Fluorescent in situ hybridization } \\ \text { FITC } & \text { Fluorescein isothiocyanate } \\ \text { LG } & \text { Linkage group } \\ \text { RAPD } & \text { Random amplification of polymorphic DNA } \\ \text { rDNA } & \text { Ribosomal DNA } \\ \text { SDS } & \text { Sodium dodecyl sulfate } \\ \text { SSC } & \text { Saline-sodium citrate }\end{array}$

\section{Introduction}

Common bean (Phaseolus vulgaris L.) is the most economically important species of the genus Phaseolus and the primary dietary protein source for several populations, mainly in Latin America and Africa (Evans 1986). In order to assist common bean breeding, several tools have been developed for this species, including genetic maps (Vallejos et al. 1992; Nodari et al. 1993; Adam-Blondon et al. 1994; Freyre et al. 1998; Hougaard et al. 2008) and bacterial artificial chromosome (BAC) libraries (Vanhouten and Mackenzie 1999; Kami et al. 2006; Gepts et al. 2008). In 2003, an international consortium named Phaseomics was created in an effort to accelerate the improvement of common bean (Broughton et al. 2003). One of the aims of this initiative was to establish a cytogenetic-based physical map for this species.

Cytogenetic maps of different plant species have been developed in fluorescent in situ hybridization (FISH) experiments using BAC clones as probes (Jiang and Gill 2006). This approach is especially recommended for constructing maps of species with a small genome because the large proportion of repetitive DNA in larger genomes may hamper the mapping of BAC clones to unique genomic positions (Jiang and Gill 1996; Dong et al. 2000; Islam-Faridi et al. 2002; Kim et al. 2005b; Pedrosa et al. 2002). Such maps are often associated with genetic and contig maps, and may be useful during wholegenome sequencing projects, either helping to evaluate the size of the putative remaining gaps (Cheng et al. 2001) or helping to decide which BACs are euchromatic and potentially gene rich and thus should be sequenced (Young et al. 2005; Peters et al. 2009).

Common bean is a small-genome species selected for whole-genome sequencing (Gepts et al. 2005), and accession G19833 is currently being sequenced by a group of US laboratories (Scott Jackson, personal communication). Its chromosomes $(2 n=22)$ are small (around $2 \mu \mathrm{m}$ ) and have similar morphologies, hindering a detailed cytogenetic characterization by classic methods. Since FISH was first applied to its mitotic chromosomes, major advances have, however, been obtained (Moscone et al. 1999; Pedrosa et al. 2003; Pedrosa-Harand et al. 2006). A preliminary FISH analysis has suggested a low general correlation between genetic and physical distances when linkage groups (LGs) and chromosomes are compared, indicating the necessity to establish a more detailed physical map (Pedrosa et al. 2003). Recently, Pedrosa-Harand et al. (2009) published a BAC FISH mapping for three 'BAT93' common bean chromosomes (chromosomes 3, 4, and 7, according to the standard common bean nomenclature proposed by Pedrosa-Harand et al. 2008), which reinforced the low correlation between genetic and physical distances in this crop.

In the present study, we extended this analysis to complete the chromosomal map of common bean. For this purpose, BACs from a genomic library from the Mesoamerican genotype BAT93 (Kami et al. 2006) were selected for the remaining eight chromosome pairs (chromosomes 1, 2, 5, 6, 8, 9, 10, and 11) and mapped by FISH. The results were compared to the corresponding genetic maps (Vallejos et al. 1992; Hougaard et al. 2008) and correlated to the distribution of different repetitive sequences on each chromosome. 


\section{Materials and methods}

Plant material

Seeds from the P. vulgaris Mesoamerican breeding line BAT93 were obtained from the germplasm bank of the International Center for Tropical Agriculture (CIAT; Cali, Colombia).

Chromosome preparation and fluorochrome staining

Root tips obtained from germinated seeds were pretreated with $2 \mathrm{mM}$ 8-hydroxyquinoline for $18 \mathrm{~h}$ at $10^{\circ} \mathrm{C}$, fixed in ethanol-acetic acid $(3: 1 \mathrm{vol} / \mathrm{vol})$, and stored in fixative at $-20^{\circ} \mathrm{C}$ for up to several weeks. Somatic chromosome preparation, selection of slides, chromomycin A3 (CMA)/4',6-diamidino-2phenylindole (DAPI) staining, and destaining for FISH were performed in accordance with Cabral et al. (2006).

Pachytene chromosome spreads were prepared as described previously, except that flower buds were fixed without pretreatment and digested in $2 \%$ (wt/vol) cellulase Onozuka R-10 (Serva), 1\% (wt/vol) pectolyase (Sigma-Aldrich), and $1 \%$ (wt/vol) cytohelicase (Sigma-Aldrich) for $2 \mathrm{~h}$ at $37^{\circ} \mathrm{C}$, and meiocytes were washed twice for $5 \mathrm{~min}$ in ice-cold $0.01 \mathrm{M}$ citric acidsodium citrate buffer ( $\mathrm{pH} 4.8$ ) and left in distilled water overnight at $4^{\circ} \mathrm{C}$ before dissection.

DNA probes

The probe D2, a 500-bp fragment containing 5S ribosomal DNA (rDNA) from Lotus japonicus (Pedrosa et al. 2002), and the probe R2, a 6.5-kb fragment of an $18 \mathrm{~S}-5.8 \mathrm{~S}-25 \mathrm{~S}$ rDNA repeat unit from Arabidopsis thaliana (Wanzenböck et al. 1997), were used to localize $5 \mathrm{~S}$ and $45 \mathrm{~S}$ rDNA sites, respectively.

BAC clones were selected by screening highdensity BAC filters from a BAT93 HindIII genomic library (Kami et al. 2006) using genetically mapped markers (the common bean genomic plasmid clone Bng), as described by Pedrosa et al. (2003) and Pedrosa-Harand et al. (2009). A second group of BAC clones was selected from the same library using the legume marker Leg (Hougaard et al. 2008), as will be described later. Finally, one $\lambda$ bacteriophage, SJ19.12, obtained after screening of a JaloEEP558 genomic library with a nucleotide-binding site probe (Ferrier-Cana et al. 2003), was also included in this analysis. Bacteriophage SJ19.12 mapped at one end of LG B10, distal to marker D1476, in the vicinity of the PROD15-680 random amplification of polymorphic DNA (RAPD) marker (Geffroy et al. 2000).

BAC and plasmid DNA were isolated using the Plasmid Mini Kit (Qiagen), whereas DNA Nucleobond AX columns (Macherey-Nagel) were used for bacteriophage isolation, both following the manufacturers' instructions. All selected clones were labelled by nick translation (Invitrogen or Roche Diagnostics) with digoxigenin-11-dUTP (Roche Diagnostics), Cy3-dUTP (5-amino-propargyl-2'-deoxyuridine 5'triphosphate coupled to red cyanine fluorescent dye; GE), or SpectrumGreen-dUTP (Vysis).

\section{Screening of BAC library with Leg}

The Laboratory of Gene Expression, Department of Molecular Biology, University of Aarhus, Denmark, provided $13 \mathrm{Leg}$ primer pairs developed using the approach described by Fredslund et al. (2005, 2006a, b) and $17 \mathrm{Leg}$ sequences of P. vulgaris BAT93 (Hougaard et al. 2008) for the LG of interest. Using these sequences, we designed primer pairs with Primer3 software (Rozen and Skaletsky 2000; http:// frodo.wi.mit.edu/). After selecting 17 low-copy or single-copy Leg probes by Southern blot or dot blot analysis, we radioactively screened the BAC library in accordance with Kami et al. (2006), with minor modifications, using two (of six) filters for each of the three pools of five to six probes. In order to assign each clone to the corresponding probe, we extracted BAC DNA following a standard alkaline lysis plasmid miniprep protocol and amplified it with the Leg primer pairs.

Dot blot analysis for detection of BACs containing repetitive DNA

Denatured BAC DNA corresponding to Bng133 and Bng152 from chromosome 5 was dot blotted onto a Nylon membrane (Hybond-N ${ }^{+}$; GE) and submitted to hybridization with the $C_{0} t-1$ fraction [where $C_{0}$ is the initial concentration of single-stranded DNA (in $\mathrm{mol} / \mathrm{L}$ ), and $t$ is the reannealing time (in s)] of $P$. vulgaris genomic DNA as probe, isolated in accor- 
dance with Zwick et al. (1997). The probe was labelled with digoxigenin using the Dig high-prime DNA labelling kit (Roche Diagnostics). The membrane was hybridized overnight with probe DNA in Dig Hyb hybridization buffer (Roche Diagnostics) at $37^{\circ} \mathrm{C}$. After hybridization, the membranes were washed twice in $2 \times$ saline-sodium citrate (SSC) buffer and $0.1 \%$ sodium dodecyl sulfate (SDS) for 5-15 min, and in $0.5 \times$ SSC buffer and $0.1 \%$ SDS for $15 \mathrm{~min}$ at $68^{\circ} \mathrm{C}$. The detection was performed using anti-DIG alkaline phosphatase conjugate (Roche Diagnostics) and the chemiluminescent substrate CDP-Star (Roche Diagnostics), according to the manufacturer's instructions. Signals were captured on an X-ray ECL film (GE).

\section{Fluorescence in situ hybridization}

The FISH procedure applied to both mitotic and meiotic chromosomes was essentially the same as previously described (Pedrosa et al. 2002). Mitotic and meiotic preparations were denatured for $5 \mathrm{~min}$ at $75^{\circ} \mathrm{C}$ and for $3 \mathrm{~min}$ at $73^{\circ} \mathrm{C}$, respectively. The P. vulgaris $C_{0} t-100$ fraction was added in 20 -fold to 400 -fold excess to the hybridization mix to block repetitive sequences when necessary. Digoxigenin-labelled probes were detected with $0.4 \mu \mathrm{l}$ of sheep antidigoxigenin conjugated with fluorescein isothiocyanate (FITC; Roche Diagnostics) and with $0.7 \mu$ of donkey anti-sheep/goat conjugated with FITC (Serotec) in 3\% bovine serum albumin in phosphate-buffered saline. Reprobing of slides for localization of different DNA sequences in the same cell was performed, in accordance with Heslop-Harrison et al. (1991, 1992), up to four times. When a repetitive probe was used in a previous hybridization, reprobing of slides was performed after the chromosomal DNA had been denatured with $100 \mu \mathrm{l}$ of $50 \%$ formamide in $2 \times$ SSC buffer at $75^{\circ} \mathrm{C}$ for $5 \mathrm{~min}$, dehydrated in an ice-cold ethanol series, and air dried.

\section{Data analysis}

Photographs were taken in an epifluorescence Leica DMLB microscope equipped with a Cohu chargecoupled device video camera using the Leica QFISH software. For final processing, images were superimposed and artificially colored using the Adobe Photoshop software version 10.0 and adjusted for brightness and contrast only. Chromosomes were named and oriented according to the standard common bean nomenclature (Freyre et al. 1998; PedrosaHarand et al. 2008).

Measurements

Relative chromosome size and arm ratio were calculated based on measurements of the chromosome and arm lengths of at least five mitotic metaphases. The centromere was determined by the presence of $\mathrm{DAPI}^{+}$bands at this position after FISH. The "measurement" tool of Adobe Photoshop was used for all size estimations, including the size of repetitive BAC signals and $45 \mathrm{~S}$ rDNA clusters in relation to chromosome size. The size of $\mathrm{DAPI}^{+}$ bands generated after FISH was measured from the more conspicuous and reproducible terminal and pericentromeric bands, and for major nucleolar organizer regions on chromosomes 9 and 10 (excluding the distended region). For each of these three categories, the total measured value was compared to the total genome size obtained by measuring all chromosome lengths. Neither the brightness nor the contrast of these pictures was adjusted for measurements in order to avoid possible distortions in signal extension.

In order to establish the relative position of each clone (single-copy BACs, bacteriophage, and rDNA sites) along the chromosomes, we selected at least 15 clear hybridization signals. In this case, the software Image Tool 3.0 was used for measurements after the contrast and the brightness of the pictures had been adjusted with Adobe Photoshop 10.0. To calculate the position of the signals, we took the following measurements: (1) the distance between the opposite telomere and the center or the start (45S rDNA) of the signal; (2) the distance between both telomeres (which gives the total chromosomal length), by prolonging the previous measurement until the closest telomere; and (3) the ratio between the first measurement and the second measurement, to determine the relative position of the signal along the chromatid. The top of the short arm was conventionally determined as 0 , and the bottom of the long arm was conventionally determined as 1 . Assignment of a clone to a specific chromosome arm was confirmed by reprobing the slides with a previously mapped clone. 


\section{Results}

In order to achieve a high genome coverage for the eight unmapped common bean chromosomes (chromosomes 1, 2, 5, 6, 8, 9, 10, and 11), we used 74 Bng markers (Vallejos et al. 1992) and 17 single-copy Leg (Hougaard et al. 2008) mapped to the corresponding LGs for screening the BAT93 BAC library (Kami et al. 2006). Following the two different approaches described previously, we identified 82 BACs for 23 Bng markers and 39 BACs for $11 \mathrm{Leg}$, making a total of 121 BACs corresponding to 34 markers (Supplementary Table 1). For the remaining markers used, no corresponding BAC could be identified.

In the present article, 35 of the above selected BACs (Table 1) - plus BAC $\mathrm{gF}_{11}$ (previously selected for LG B8 by Melotto et al. 2004), one bacteriophage (SJ19.12, mapped to LG B10), and two plasmids (containing 5S and 45S rDNA sequences)-were hybridized in situ. The other BACs listed in Supplementary Table 1 were not used for FISH because they were selected with the same markers or mapped genetically very close to localized clones. Considering all the 36 BACs hybridized in the present article and 30 BACs hybridized previously (Pedrosa-Harand et al. 2009), making a total of 66 BACs used for constructing a cytogenetic map for common bean, we observed that only 39 (59\%) showed unique localized signals in just one chromosome pair; however, for half of them (18 BACs), the use of $C_{0} t-1$ or $C_{0} t-100$ blocking DNA in the hybridization mix (20-fold to 100 -fold more concentrated than the probe) was necessary in order to eliminate labelling of dispersed repetitive sequences and to obtain unique signals. Although selected with single-copy markers, 25 BACs (38\%) showed highly repetitive signals, predominantly pericentromeric or subtelomeric, in all chromosomes and could not be mapped. The remaining two BACs did not give a signal.

Many attempts to block pericentromeric and subtelomeric sequences present in repetitive BACsfrom using $C_{0} t$ genomic fractions as general blocker to using a specific blocker (khipu satellite) for subtelomeric BACs-were performed (David et al. 2009; K.G.B. dos Santos, unpublished data). However, none of the attempts was successful (data not shown), possibly because the proportion of these repetitive sequences in the genome is too high. Nevertheless, it was possible to remove subtelomeric signals (but not the pericentromeric ones) from slides, making them useful for rehybridization with other probes.

Hybridization signals of $15 \mathrm{BACs}$, showing practically the same pattern in the pericentromeric region of all chromosomes and corresponding approximately to $34 \%$ of the chromosome complement length, coincided with the $\mathrm{CMA}^{+}$bands generated after CMA/DAPI staining (Fig. 1a, b), except for bands corresponding to $45 \mathrm{~S}$ rDNA sites. After the FISH procedure, small $\mathrm{DAPI}^{+}$bands were sometimes also visible at the centromeric region of mitotic chromosomes, corresponding to $12 \%$ of the chromosome complement length (Fig. 1c). However, no BAC used in this work showed a similar centromeric hybridization pattern. These centromeric $\mathrm{DAPI}^{+}$bands possibly correspond to centromeric repeats not interspersed with single-copy sequences and, therefore, not isolated by our screening. On the other hand, terminal $\mathrm{DAPI}^{+}$bands, generated after FISH, coincided either with major $45 \mathrm{~S}$ rDNA sites or with regions labelled by five subtelomeric BACs (Fig. 1f), corresponding to $5 \%$ and $9 \%$ of the chromosome complement length, respectively. Considering both $\mathrm{CMA}^{+}$and DAPIafter-FISH bands as indicative of constitutive heterochromatin (see "Discussion"), we estimate that $48 \%$ of the common bean somatic karyotype is heterochromatic $(5 \%$ of rDNA, $9 \%$ of other subtelomeric blocks, and $34 \%$ of pericentromeric blocks). Although this fraction is visibly enriched in repetitive sequences, it is also populated by single-copy sequences, and likely by genes, since single-copy markers are present in the inserts of BACs showing heterochromatin distribution.

Although single-copy sequences are generally more efficient for chromosome identification (Figs. 2, $3,4)$, BACs showing repetitive hybridization patterns were very informative in this study. With only one single-copy BAC (BAC 177I19 for chromosome 8) and three repetitive BACs [one pericentromeric (BAC 12M3), one subtelomeric (BAC 63H6), and one showing a repeat block in chromosome 7 (BAC $255 \mathrm{~F} 18)$ ], it was possible to identify each chromosomal pair of 'BAT93' through differences in signal intensity and localization, combined with chromosome size. A BAC for chromosome 5 (36H21) confirmed its correct identification by the four-BAC pool probe (Fig. 3e-g). The rDNA-bearing chromosomes (chromosomes 6, 9, and 10) could be alterna- 
Table 1 List of mapped markers used for screening BAC clones and the general pattern of hybridization of the selected BACs after FISH with or without blocking DNA

\begin{tabular}{|c|c|c|c|c|}
\hline $\mathrm{LG}^{\mathrm{a}}$ & Marker $^{\mathrm{b}}$ & BAC clone & FISH pattern without blocking DNA & FISH pattern with blocking DNA \\
\hline \multirow[t]{3}{*}{$\mathrm{B} 1 / \mathrm{H}$} & Bng41 & $221 \mathrm{~F} 15$ & Unique + weakly scattered & Unique $\left(20 \times C_{0} t-100\right)$ \\
\hline & Bng171 & $38 \mathrm{C} 24$ & Unique & - \\
\hline & Bng173 & $257 \mathrm{~L} 12$ & Unique & - \\
\hline \multirow[t]{8}{*}{$\mathrm{B}_{2} / \mathrm{D}$} & $4-G m$ & $21 \mathrm{~N} 14$ & Disperse proximally & Unique $\left(80 \times C_{0} t-100\right)$ \\
\hline & Bng45 & $225 \mathrm{P} 10$ & Unique & - \\
\hline & Bng57 & $14 \mathrm{~F} 2$ & Subtelomeric & Subtelomeric $\left(100 \times C_{0} t-100\right)$ \\
\hline & & $18 \mathrm{D} 16$ & Disperse proximally + one terminal block & Disperseproximally $\left(20 \times C_{0} t-1\right)$ \\
\hline & Bng174 & $92 \mathrm{I} 7$ & Pericentromeric & - \\
\hline & $L 120$ & $82 \mathrm{~K} 2$ & No signal & - \\
\hline & $L 188$ & $127 \mathrm{~F} 19$ & Unique & - \\
\hline & $L 224$ & $17 \mathrm{P} 14$ & Subtelomeric & - \\
\hline \multirow[t]{4}{*}{$\mathrm{B} 5 / \mathrm{E}$} & Bng49 & $36 \mathrm{H} 21$ & Disperse & $\operatorname{Unique}\left(70 \times C_{0} t-100\right)$ \\
\hline & Bng133 & $230 \mathrm{M} 2$ & Pericentromeric & - \\
\hline & Bng152 & $193 \mathrm{O} 2$ & Pericentromeric & - \\
\hline & Bng161 & 103P12 & Pericentromeric & Pericentromeric $\left(400 \times C_{0} t-100\right)$ \\
\hline \multirow[t]{4}{*}{$\mathrm{B} 6 / \mathrm{G}$} & Bng95 & $121 \mathrm{~F} 5$ & Unique & - \\
\hline & Bng177 & $143 \mathrm{~N} 10$ & Pericentromeric & - \\
\hline & Bng202 & $18 \mathrm{~B} 15$ & Unique & - \\
\hline & L56 & $260 \mathrm{H} 1$ & Pericentromeric & - \\
\hline \multirow[t]{3}{*}{$\mathrm{B} 8 / \mathrm{F}$} & Bng58 & 169G16 & Disperse & Unique $\left(50 \times C_{0} t-100\right)$ \\
\hline & Bng96 & $234 \mathrm{P} 20$ & Subtelomeric & Subtelomeric $\left(50 \times C_{0} t-100\right)$ \\
\hline & Bng138 & $177 \mathrm{I} 19$ & Unique & - \\
\hline \multirow[t]{4}{*}{$\mathrm{B} 9 / \mathrm{K}$} & Bng2 & $224 \mathrm{I} 16$ & Unique + weakly scattered & Unique $\left(50 \times C_{0} t-100\right)$ \\
\hline & $L 159$ & $123 \mathrm{O} 22$ & Pericentromeric & Pericentromeric $\left(50 \times C_{0} t-100\right)$ \\
\hline & L206 & $37 \mathrm{P} 17$ & No signal & - \\
\hline & L207 & $163 \mathrm{I} 7$ & Unique + weakly scattered & Unique $\left(20 \times C_{0} t-100\right)$ \\
\hline \multirow[t]{4}{*}{$\mathrm{B} 10 / \mathrm{I}$} & Bng200 & 173P6 & Unique + weakly scattered & Unique $\left(20 \times C_{0} t-100\right)$ \\
\hline & Bng218 & $63 \mathrm{H} 6$ & Subtelomeric & - \\
\hline & & $81 \mathrm{~A} 17$ & Pericentromeric & - \\
\hline & $L 177$ & 119E19 & Subtelomeric & - \\
\hline \multirow[t]{5}{*}{$\mathrm{B} 11 / \mathrm{J}$} & Bngl & $25 \mathrm{D} 1$ & Disperse & Unique $\left(60 \times C_{0} t-100\right)$ \\
\hline & Bng25 & $255 \mathrm{~F} 18$ & Unique + one terminal block & - \\
\hline & Bng112 & $179 \mathrm{~N} 14$ & Unique & - \\
\hline & Bng187 & $66 \mathrm{~N} 11$ & Pericentromeric & - \\
\hline & $L 220$ & $127 \mathrm{~J} 2$ & Unique + weak subtelomeric & - \\
\hline
\end{tabular}

(-) Not analyzed.

${ }^{\text {a }}$ LGs D, E, and so on, defined by Vallejos et al. (1992), corresponding to LGs B2, B5, and so on from the common bean core map (Freyre et al. 1998), as indicated previously.

${ }^{\mathrm{b}}$ Bng markers were mapped by Vallejos et al. (1992) on the Florida map, while markers 4-Gm and Leg were mapped by Hougaard et al. (2008) on another mapping population.

tively distinguished by the distribution of their repetitive sequences (Fig. 4).

Eighteen selected BACs plus BAC $\mathrm{gF}_{11}$ (selected with the SAS13 marker from the anthracnose resis- tance locus $C_{0}-4$ ) and bacteriophage SJ19.12 were mapped to the eight chromosomes analyzed in the present study (Table 2 and Figs. 2, 3, 4). On average, two clones were mapped per chromosome, but only 

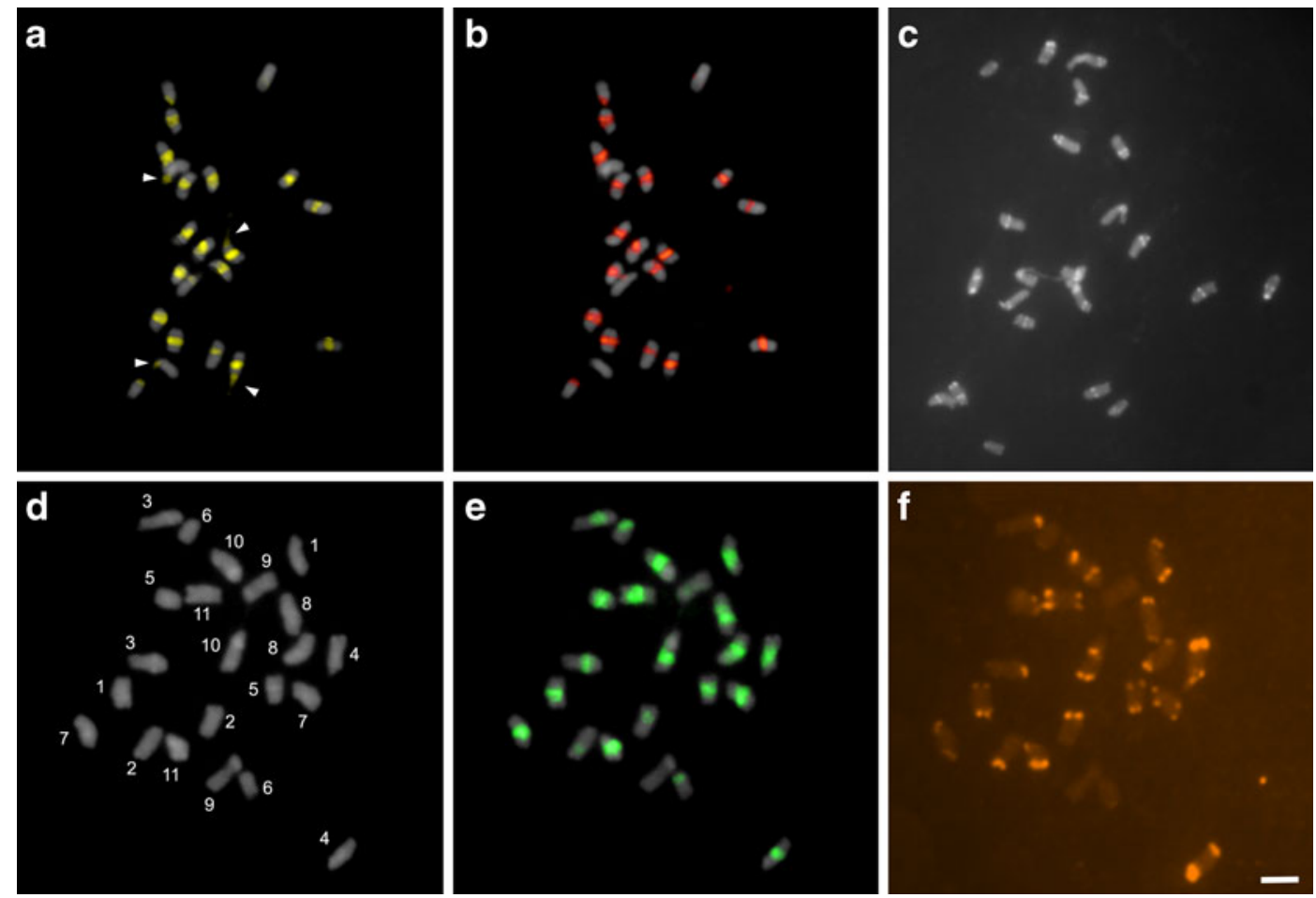

Fig. 1 Repetitive-rich regions visualized on mitotic chromosomes of common bean. a CMA banding pattern (45S rDNA loci on chromosomes 9 and 10 are indicated by arrowheads). b In situ hybridization of BAC 12M3, labelled with Cy3-dUTP fluorochrome in the same cell as (a), showing a pericentromeric pattern corresponding to $\mathrm{CMA}^{+}$pericentromeric bands. c $\mathrm{DAPI}^{+}$bands after FISH. $\mathbf{d}-\mathbf{f}$ In situ hybridization of repetitive

one BAC (36H21) could be mapped to chromosome 5. After dot blot analysis using the $C_{0} t-1$ genome fraction as probe, no other BAC identified for this chromosome was selected for FISH, since all showed strong hybridization signals indicative of the presence of highly repetitive DNA in its insert (data not shown). For chromosome 1, two BACs were colocalized on the distal region of the long arm (Fig. 2a). In order to have a higher-resolution mapping of the colocalized BACs, we used pachytene chromosomes, providing evidence that BAC $257 \mathrm{~L} 12$ is more terminally located (Fig. 2a, bottom insert).

Based on previous (Pedrosa-Harand et al. 2009) and present data, an idiogram was built for common bean (Fig. 5). P. vulgaris cv. BAT93 has three metacentric chromosomes (chromosomes 4, 5, and 8), seven submetacentric chromosomes (chromosomes $1,2,3,7,9,10$, and 11), and one acrocentric chromosome (chromosome 6), according to the
BACs in the same cell. d DAPI counterstaining (chromosome numbers are indicated). e BAC $12 \mathrm{M} 3$, labelled with a SpectrumGreen-dUTP fluorochrome, showing a pericentromeric pattern. f BAC 63H6, labelled with Cy3-dUTP, showing a subtelomeric pattern. Chromosomes are counterstained with DAPI and visualized in gray, except in (f). Bar in (f) represents $2.5 \mu \mathrm{m}$

morphology classification of dos Santos Guerra (1986). Chromosomes 6 and 10 have both $5 \mathrm{~S}$ and 45S rDNA sites. An additional 45S rDNA site is present on chromosome 9. Pericentromeric repetitive sequences, identified by pericentromeric BACs, were present on all chromosomes as very evident blocks, except on chromosome 6, which labelled a small region, and chromosome 9, with an even smaller one. Subtelomeric repetitive sequences, present in BACs with this hybridization pattern, were visualized on all chromosomes, except for chromosome 9. Chromosomes $1,4,5,7,8,10$, and 11 presented subtelomeric sites on both arms, although some with different sizes, while chromosomes 2,3 , and 6 presented only one site each, but with different sizes.

Four BACs were mapped to chromosome 11, two to each arm. BAC 225F18, localized proximally on the short arm, showed an additional prominent signal terminally on the long arm of chromosome 7 

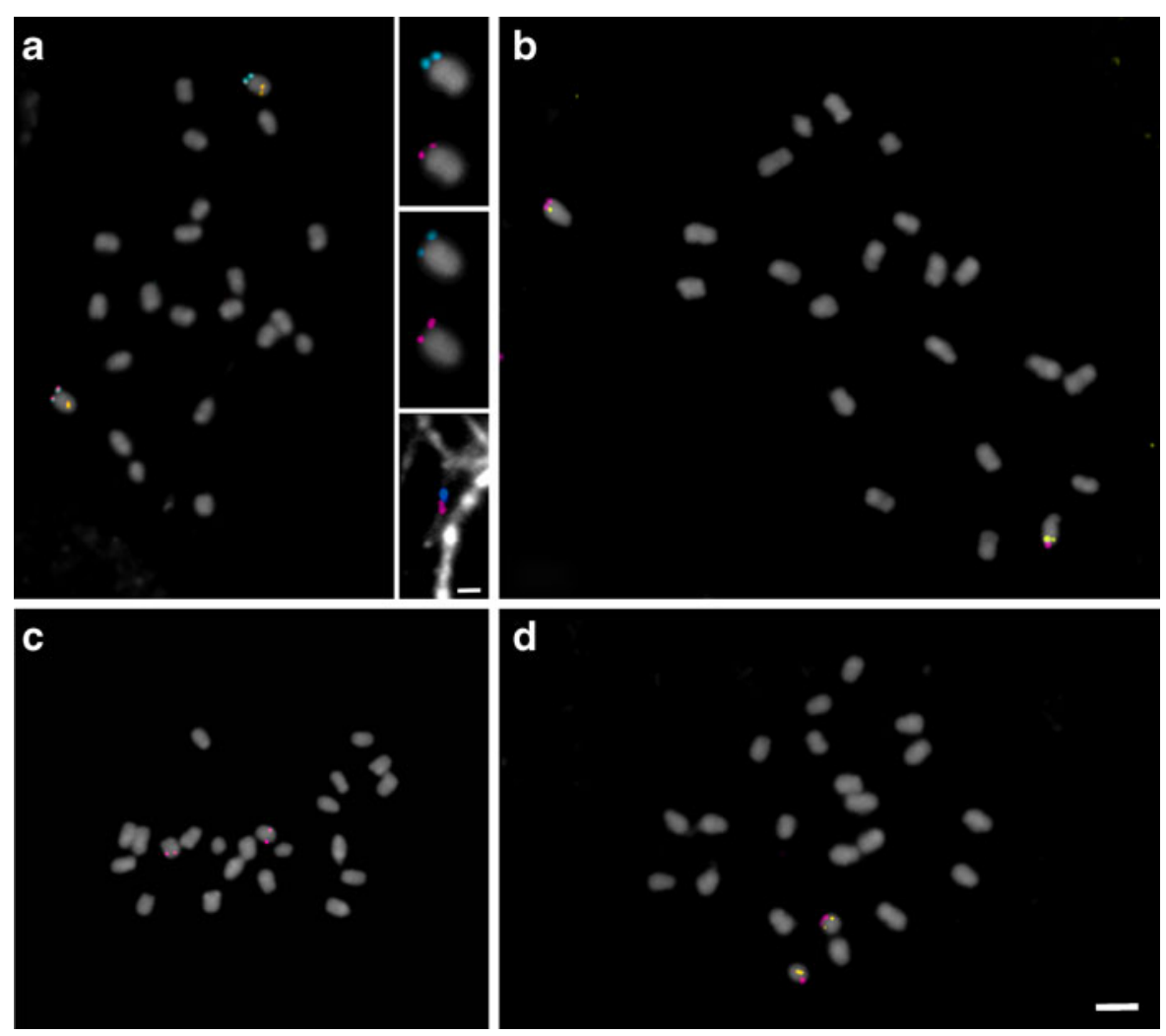

Fig. 2 In situ hybridization of genetically assigned BACs to common bean mitotic and pachytene chromosomes. a BACs mapped to chromosome 1: 257L12 (pink), 38C24 (blue), and 221F15 (yellow). The top and middle inserts show each homologous chromosome twofold enlarged with individual signals of BACs $257 \mathrm{~L} 12$ (pink) and 38C24 (blue), respectively.

(Fig. 3e), corresponding to a new repetitive DNA sequence (T.R.B. dos Santos et al., manuscript in preparation). While the distance between the DNA markers corresponding to BACs $225 \mathrm{~F} 18$ and $179 \mathrm{~N} 14$ corresponds to almost $50 \%$ of the LG size, the physical distance between them only represents $8 \%$ of the total chromosomal length. Similarly, the physical distance between BACs $163 \mathrm{I} 7$ and 224I16, from the long arm of chromosome 9, was equivalent to $36 \%$ of the total chromosomal length, but the estimated genetic distance between their DNA markers probably corresponds to ca. $90 \%$ of the LG. These data suggest a higher recombination rate along these chromosome arms. On the other hand, a comparison of genetic and physical distances between Bng25 (225F18) and Bngl (25D1) from chromosome 11 revealed suppression of recombination in the pericentromeric region.
The bottom insert shows both BACs on pachytene chromosomes (bar, $1 \mu \mathrm{m})$. b BACs mapped to chromosome 2: 225P10 (pink) and 127F19 (yellow). c BAC mapped to chromosome 5: 36H21 (pink). d BACs mapped to chromosome 6: 18B15 (pink) and 121F5 (yellow). Chromosomes are counterstained with DAPI and visualized in gray. Bar in (d) represents $2.5 \mu \mathrm{m}$

\section{Discussion}

In this article, we present the mapping of the remaining eight chromosome pairs of common bean using 20 clones that gave unique sequences with or without blocking DNA, complementing the previous mapping of chromosomes 3, 4, and 7 (PedrosaHarand et al. 2009). We also propose a set of four $\mathrm{BAC}$ clones that can be used to recognize all chromosomes of the complement of BAT93, aiding future mapping. This is the third cytogenetic map of a legume species, after L. japonicus (Pedrosa et al. 2002) and Medicago truncatula (Kulikova et al. 2001), and the first for a tropical legume. Because of its proximity to other economically important species from the phaseoloids clade such as soybean and cowpea (Gepts et al. 2005), it will be useful for further syntenic studies in the group, especially considering 
Fig. 3 In situ hybridization of genetically assigned and repetitive clones to common bean mitotic chromosomes. a BACs mapped to chromosome 8: 169G16 (yellow) and 177I19 (pink). b BACs mapped to chromosome 9: $163 \mathrm{I} 7$ (pink) and 224I16 (yellow). c Clones mapped to chromosome 10: SJ19.12 (pink) and 173P6 (yellow). d BACs mapped to chromosome 11: 25D1 (pink) and 179N14 (yellow). $\mathbf{e}^{-} \mathbf{g}$ In situ hybridization of repetitive and single-copy BACs in the same cell. e DAPI counterstaining. f BAC clones: 63H6 (subtelomeric; orange), 12M3 (pericentromeric; green), 225F18 (chromosomes 7 and 11; blue), and 177I19 (chromosome 8 ; pink). Identification of chromosome 5 was confirmed by hybridizing with 36H21 (yellow). g Karyogram where all 11 chromosome pairs are identified. Chromosomes are counterstained with DAPI and visualized in gray. Bar represents $2.5 \mu \mathrm{m}$ in (f) and $2 \mu \mathrm{m}$ in (g)
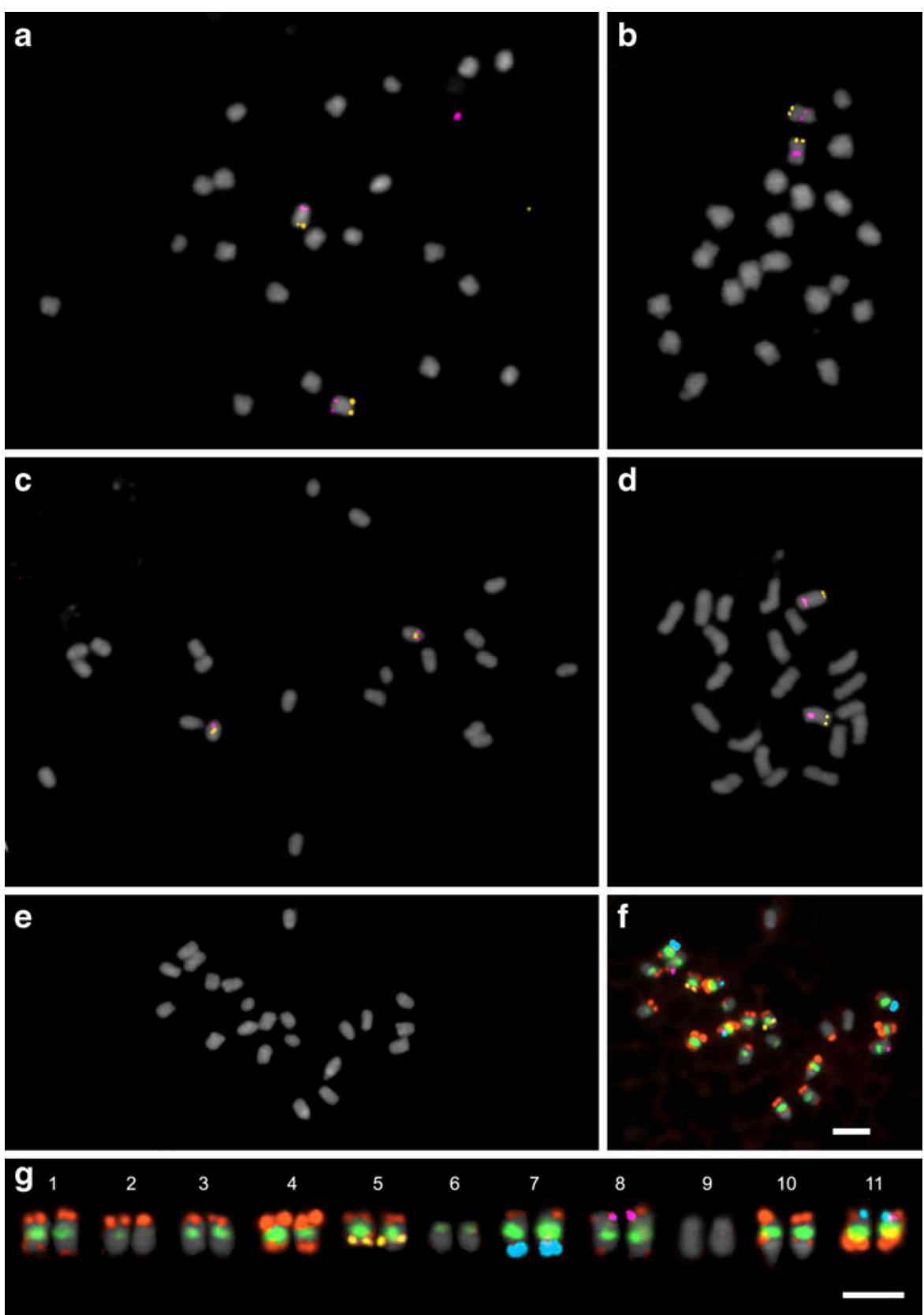

the tetraploid nature of soybean (Shoemaker et al. 2006; Schlueter et al. 2008).

The common bean cytogenetic map presented here is integrated into the core linkage map of the species (Freyre et al. 1998) through BACs selected using markers from the Florida map (Vallejos et al. 1992) and the recently developed map using comparative anchor-tagged sequence loci (Hougaard et al. 2008). Except for chromosome 5, for which only one anchoring point could be established, LGs were assigned and oriented in respect to chromosome short and long arms, confirming the orientation of LGs and chromosomes recently proposed (Pedrosa-Harand et al. 2008). LG I (Vallejos et al. 1992) corresponds to the short arm and part of the long arm of chromosome 10 only because the BAC corresponding to the terminal Bng200 marker mapped to the middle of the long arm. Although the long arm has a large 


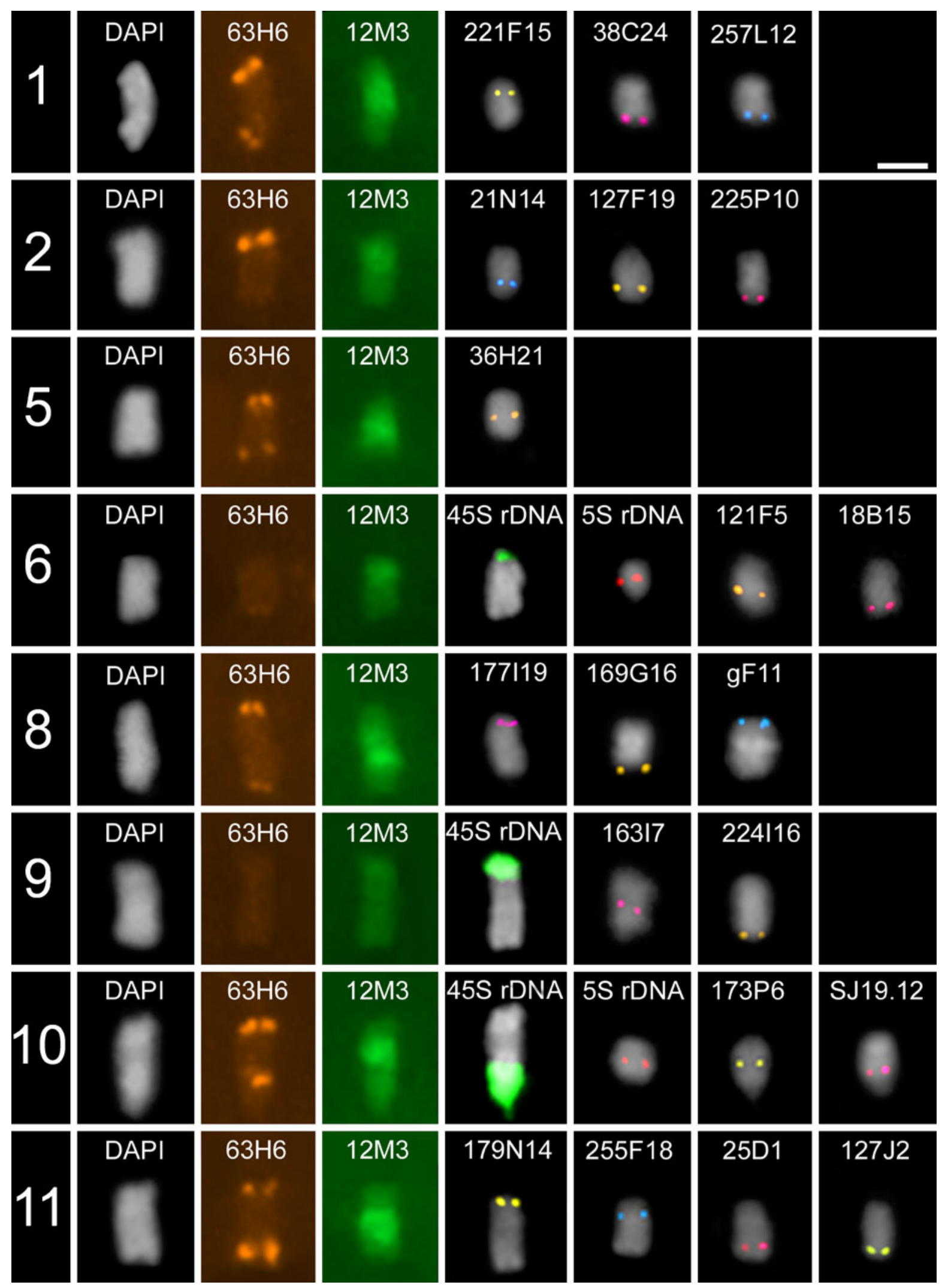


Fig. 4 Physical localization of BAC clones to P. vulgaris 'BAT93' mitotic chromosomes counterstained with DAPI (gray). Subtelomeric (63H6) and pericentromeric (12M3) repetitive BACs are shown in orange and green, respectively, and were isolated from the same cell in order to show the relative intensity of the signals among chromosomes. Unique clones (yellow, blue, and pink) are ordered according to their distribution along arms (from top to bottom). The $5 \mathrm{~S}$ (red) and 45S (green) rDNA loci are also shown. Chromosomes 3, 4, and 7 were not included here because they had been previously mapped (Pedrosa-Harand et al. 2009). Bar on top represents $5 \mu \mathrm{m}$

terminal 45S rDNA cluster, the position of the clones mapped to this chromosome indicates that LG I does not have good coverage. Indeed, more terminal markers were mapped to the corresponding LG 10
(Hougaard et al. 2008), including an rDNA locus (Freyre et al. 1998) and an RAPD marker PROD15 $5^{680}$ (Geffroy et al. 2000), in the vicinity of which the bacteriophage SJ19.12 was mapped. LGs G and K, on the other hand, apparently only correspond to the long arms of chromosomes 6 and 9, respectively. In both cases, short arms seem to be composed mainly of $45 \mathrm{~S}$ rDNA. The $45 \mathrm{~S}$ rDNA locus on chromosome 6 has been observed in all accessions of $P$. vulgaris investigated so far (Moscone et al. 1999; Pedrosa et al. 2003; Pedrosa-Harand et al. 2006). Variations in the size of this cluster were correlated with the arm and chromosome sizes. Indeed, although chromosome 6 is acrocentric and is the smallest chromosome in 'BAT93,' it is metacentric and the largest in 'Saxa'
Table 2 Genetic locations of markers and the physical locations of their associated BACs on the respective LGs and mitotic metaphase chromosomes

\footnotetext{
${ }^{\mathrm{a}}$ The position of a genetic marker on the genetic map is indicated as a percentage of the total LG length, calculated from data presented by Vallejos et al. (1992). Markers 4-Gm, Leg, and SAS13 were mapped on other populations; thus, their approximate genetic position is indicated in the idiogram only.

${ }^{b}$ The position of BACs along the chromosome is indicated as a percentage of total chromosome length, with the telomere of the short arm indicated as 0.00 and with the telomere of the long arm indicated as 1.00 .

${ }^{\mathrm{c}}$ A stronger additional signal was mapped to chromosome 7 at position $0.89 \pm$ $0.04(n=15)$.
}

\begin{tabular}{|c|c|c|c|c|c|}
\hline \multicolumn{2}{|c|}{ Genetic map } & \multicolumn{4}{|l|}{ Cytogenetic map } \\
\hline Marker & Position $^{\mathrm{a}}$ & Clone & Mean $^{\mathrm{b}}$ & $n$ & Standard deviation \\
\hline \multicolumn{6}{|c|}{ Chromosome $1 / \mathrm{H}$} \\
\hline Bng41 & 0.15 & BAC $221 \mathrm{~F} 15$ & 0.23 & 15 & 0.03 \\
\hline Bng171 & 0.96 & BAC $38 \mathrm{C} 24$ & 0.91 & 15 & 0.03 \\
\hline Bng173 & 0.98 & BAC $257 \mathrm{~L} 12$ & 0.91 & 15 & 0.04 \\
\hline \multicolumn{6}{|c|}{ Chromosome 2/D } \\
\hline $4-G m$ & - & BAC 21N14 & 0.71 & 15 & 0.05 \\
\hline$L 188$ & - & BAC $127 \mathrm{~F} 19$ & 0.71 & 15 & 0.06 \\
\hline Bng45 & 1.00 & BAC $225 \mathrm{P} 10$ & 0.93 & 15 & 0.02 \\
\hline \multicolumn{6}{|c|}{ Chromosome 5/E } \\
\hline Bng49 & 0.54 & BAC $36 \mathrm{H} 21$ & 0.65 & 15 & 0.05 \\
\hline \multicolumn{6}{|c|}{ Chromosome $6 / \mathrm{G}$} \\
\hline Bng95 & 0.33 & BAC $121 \mathrm{~F} 5$ & 0.61 & 15 & 0.05 \\
\hline Bng202 & 1.00 & BAC 18B15 & 0.85 & 15 & 0.04 \\
\hline \multicolumn{6}{|c|}{ Chromosome $8 / \mathrm{F}$} \\
\hline$S A S 13$ & - & $\mathrm{BAC} \mathrm{gF}_{11}$ & 0.08 & 15 & 0.02 \\
\hline Bng138 & 0.08 & BAC 177I19 & 0.19 & 15 & 0.03 \\
\hline Bng58 & 0.80 & BAC 169G16 & 0.92 & 15 & 0.03 \\
\hline \multicolumn{6}{|c|}{ Chromosome $9 / \mathrm{K}$} \\
\hline L207 & - & BAC $163 \mathrm{I} 7$ & 0.56 & 15 & 0.02 \\
\hline Bng2 & 1.00 & BAC 224I16 & 0.92 & 15 & 0.02 \\
\hline \multicolumn{6}{|c|}{ Chromosome 10/I } \\
\hline \multirow[t]{2}{*}{ Bng200 } & 1.00 & BAC 173P6 & 0.53 & 15 & 0.02 \\
\hline & - & Phage SJ19.12 & 0.59 & 15 & 0.05 \\
\hline \multicolumn{6}{|c|}{ Chromosome $11 / \mathrm{J}$} \\
\hline Bng112 & 0.00 & BAC $179 N 14$ & 0.08 & 15 & 0.03 \\
\hline Bng25 & 0.51 & $\mathrm{BAC} 255 \mathrm{~F} 18^{\mathrm{c}}$ & 0.25 & 15 & 0.04 \\
\hline Bngl & 0.79 & BAC 25D1 & 0.67 & 15 & 0.04 \\
\hline$L 220$ & - & BAC $127 J 2$ & 0.87 & 15 & 0.04 \\
\hline
\end{tabular}




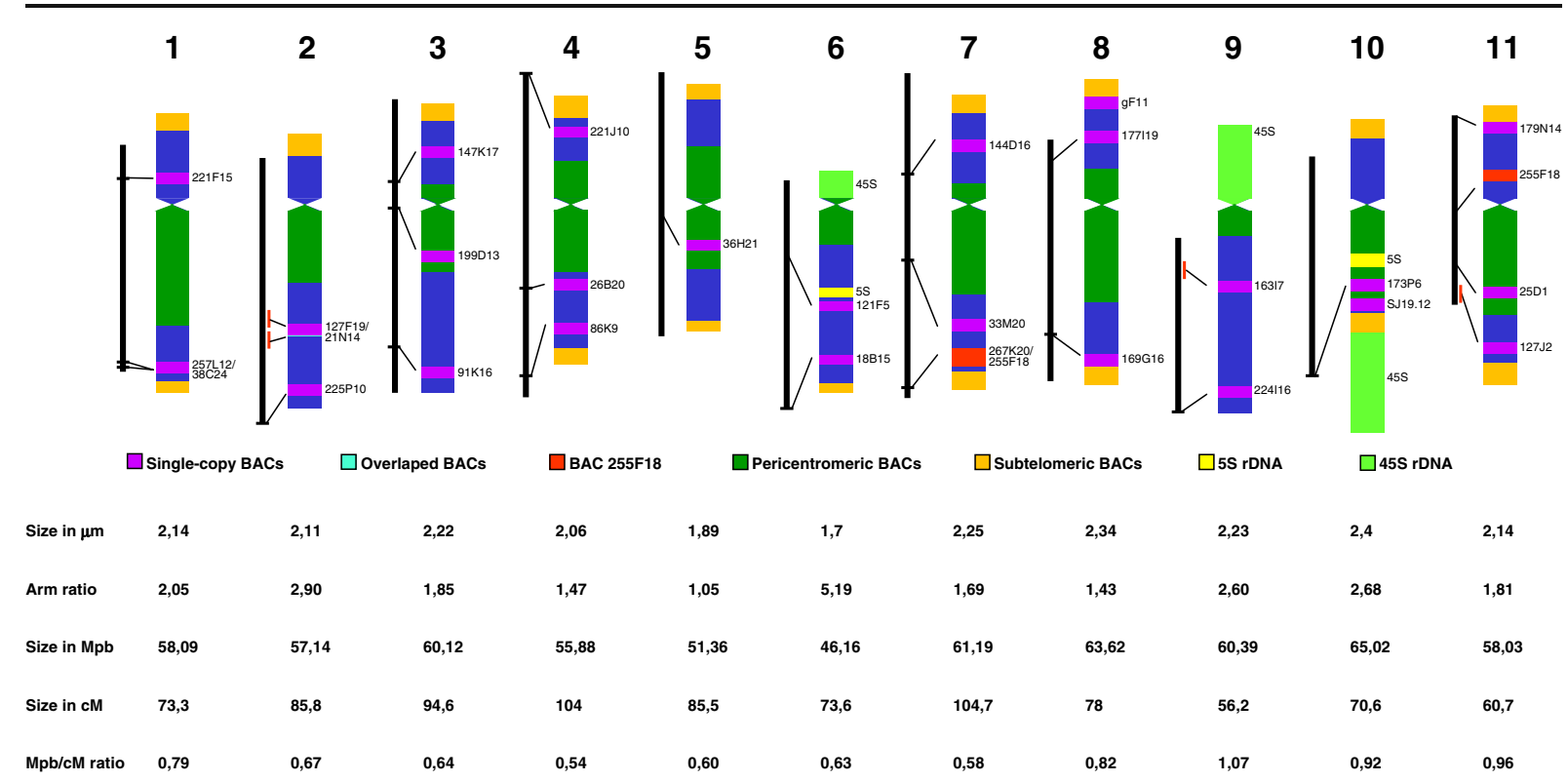

Fig. 5 Idiogram of common bean in comparison to its genetic linkage map established by Vallejos et al. (1992). The position of Leg on LGs from the Florida map is tentatively indicated by vertical bars and based on the position of those markers in the core map (Hougaard et al. 2008). The idiogram shows the relative chromosome length, position of centromeres, distribution of pericentromeric and subtelomeric heterochromatin,

(Moscone et al. 1999; present results). Chromosome 9 also seems to carry a conserved rDNA locus (Pedrosa-Harand et al. 2006), but its morphology had not been correctly established before. It was initially considered to be metacentric (Moscone et al. 1999; Pedrosa et al. 2003), but its centromere was probably misidentified due to lack of a conspicuous primary constriction. The presence of pericentromeric repetitive sequences adjacent to the terminal rDNA cluster and the occasional observation after FISH of the DAPI staining of positive dots in the same region indicate that this chromosome is submetacentric in 'BAT93' and probably in all accessions of the species.

The order of markers in the LG was in complete agreement with the order of the corresponding BACs along the chromosomes. For chromosome 1, two BAC clones 38C24 and 257L12, corresponding to Bng171 and Bng173, respectively, colocalized on mitotic chromosomes, but could be ordered after mapping on pachytene chromosomes. BAC 257L12 mapped more terminally than $38 \mathrm{C} 24$, corresponding to the more terminal position of Bng173 relative to Bng171 in the LG. These BACs were adjacent to each other in pachytene chromosomes, confirming their close physical proximity

rDNA loci, and position of the mapped clones. The sizes of the subtelomeric blocks revealed by BAC $63 \mathrm{H} 6$ are only approximate. All other sizes and positions are based on measurements (see "Materials and Methods"). For chromosomes 3, 4, and 7, only a few BACs mapped by PedrosaHarand et al. (2009) are indicated. Chromosome 10 was used for normalizing chromosome and LG lengths

and explaining the difficulty in ordering these markers with high confidence on the genetic map (Vallejos et al. 1992). The map of chromosome 11 confirmed the suppression of recombination in extended pericentromeric chromosome regions observed previously (Pedrosa-Harand et al. 2009): less than a quarter of the LG length corresponded to more than half of the chromosome size. The mapping of heterochromatin along chromosomes indicated that suppression of recombination correlates with the presence of prominent pericentromeric heterochromatic blocks (see Fig. 5).

The pericentromeric heterochromatin was defined by the repetitive distribution pattern of BAC $12 \mathrm{M} 3$, which gave pericentromeric signals, and the colocalization of these regions with the bright $\mathrm{CMA}^{+}$bands after CMA/DAPI staining (see also Zheng et al. 1993). The BAC clone that mapped more proximally on the long arm of chromosome 11, BAC 25D1, and two other BACs $(36 \mathrm{H} 21$ and 173P6) mapped to pericentromeric heterochromatin and needed the addition of $C_{0} t-100$ blocking DNA to give singlecopy signals. Blocking was, however, also necessary for some BACs that mapped to euchromatin. The occurrence of many BACs containing repetitive 
sequences, although all had been selected with singlecopy markers, indicates that unique sequences are frequently interspersed with repetitive sequences, confirming the less compartmentalized nature of the common bean genome (Pedrosa-Harand et al. 2009). In complete agreement with this hypothesis, sequencing of the B4 resistance gene cluster in BAT93, combined with FISH experiments, revealed that lowcopy genes were interspersed with repetitive sequences (Geffroy et al. 2009; David et al. 2010).

The high proportion of repetitive sequences intermingled with single-copy sequences in euchromatin and heterochromatin is not the only prominent feature of the relatively small common bean genome (approximately $600 \mathrm{Mb}$; Arumuganathan and Earle 1991). Half (48\%) of its genome was estimated to be heterochromatic based on the proportion of rDNA (5\% of the genome), subtelomeric blocks (9\%), and pericentromeric blocks (34\%) on mitotic chromosomes. This value may be underestimated because small regional heterochromatic regions are not detectable by the cytological procedures used (Houben et al. 2003), but it correlates well with estimates of the proportion of repetitive sequence (49.3\%; Schlueter et al. 2008) and the proportion of methylated DNA (60\%), obtained by methyl filtration of common bean (BAT93) DNA (P. Gepts, unpublished data). It is, however, larger than previous estimates for the heterochromatin content of the species (approximately 10\% and 21\%), which were based on centromeric DAPI $^{+}$bands after FISH (Moscone et al. 1999) and C-bands (Zheng et al. 1991), respectively. It is also considered high when compared to estimates for other species based on measurements of heterochromatin revealed by C-banding or CMA/DAPI staining (see, for example, Guerra 1993). Furthermore, it is similar to the estimated heterochromatin content from sorghum, which has a larger genome $(818 \mathrm{Mb}$; Kim et al. 2005a), although smaller than estimates based on pachytene-condensed regions from M. truncatula $(60 \%$ of 560-580 Mb; Kulikova et al. 2004). Interestingly, the pericentromeric heterochromatin of the species can be clearly subdivided into two different domains: the pericentromeric region, corresponding to BAC $12 \mathrm{M} 3$ distribution, $\mathrm{CMA}^{+}$bands, probably the strongly condensed pachytene regions (Pedrosa-Harand, unpublished data), and the C-bands described in previous publications (Zheng et al. 1991; Moscone et al. 1999), and the centromeric region, revealed by DAPI after some FISH experiments and corresponding to only about $12 \%$ of the chromosome length. None of the hybridized BACs selected with genetically mapped markers showed a "centromeric" distribution, possibly due to the lack of single-copy dispersed sequenced in this domain. We hypothesize that the centromeric regions may be composed mainly of tandemly repeated sequences, while the pericentromeric regions surrounding the centromere are composed of dispersed repetitive sequences interspersed with single-copy sequences, leading to distinct stainability after different banding procedures of these two heterochromatic domains. Supporting this hypothesis, subcloning and sequencing of pericentromeric BACs identified retroelement-like sequences in their inserts (K.G.B. dos Santos et al., manuscript in preparation). This marked difference is, however, not clear in the centromere structure of other plant species studied so far, such as Arabidopsis, rice, and maize, because the centromeres of these species are composed of intermingled satellite repeats, centromere-specific retrotransposons, and genes (Nagaki et al. 2004; Ma et al. 2007; Yan and Jiang 2007; Gill et al. 2008). Therefore, it is possible that the proportion of these different types of sequences, rather than their presence or absence, defines these different chromatin domains.

It is worth noting that the bands obtained with DAPI after the FISH procedure are different from the $\mathrm{CMA}^{+}$bands that, because of their extension, probably correspond to the previously reported C-bands (Zheng et al. 1991, 1993; Moscone et al. 1999). DAPI-after-FISH bands have been considered as largely equivalent to $\mathrm{C}$-bands in common bean and other species (Moscone et al. 1996, 1999; Barros e Silva and Guerra 2009), but we demonstrate that they correspond to only a small fraction of the pericentromeric heterochromatin in common bean. Consequently, estimates of heterochromatin content based exclusively on DAPI-after-FISH bands should be considered with caution. A combination of different approaches is more likely to reveal the heterochromatin of a species in its totality and complexity.

We demonstrate that the genome of common bean is composed of 52\% euchromatin enriched with single-copy sequences interspersed with dispersed repeats, $31 \%$ of pericentromeric heterochromatin (22\%, excluding $12 \%$ of centromeric heterochromatin) and subtelomeric (9\%) heterochromatin enriched with dispersed and tandem repeats interspersed with single-copy genetically mapped sequences, and $17 \%$ 
of rDNA (5\%) and centromeric (12\%) heterochromatin composed of repeats probably organized in tandem and largely devoid of low-copy-number genes. The tandem arrangement of the repeats in the subtelomeric heterochromatin of common bean has been demonstrated (David et al. 2009). This organization has implications for the strategy defined for sequencing the common bean genome. In practice, only the latter relatively small fraction (17\%) could be left aside during a genome sequencing endeavor, considering that most of the heterochromatin also contains genes that should be sequenced. Therefore, a whole-genome approach, such as the selected whole-genome shotgun sequencing strategy (Scott Jackson, personal communication), is more appropriate. We should also anticipate the difficulty of dealing with a high proportion of repetitive sequences in the common bean genome (Schlueter et al. 2008) and possibly the need for further BAC FISH mapping for ordering contigs or estimating gaps, as performed in tomato (Peters et al. 2009). Furthermore, this organization suggests that the heterochromatin should be considered as a heterogeneous chromosomal domain (see Chang et al. 2008) even in a species with a small genome.

Acknowledgements We thank Alba Torres (CIAT) for providing the seeds, Dr. Maeli Melotto (University of Texas at Arlington) for BAC $\mathrm{gF}_{11}$, Dr. C. Eduardo Vallejos (University of Florida) for the Bng clones, and the Laboratory of Gene Expression, Department of Molecular Biology, University of Aarhus, for the Leg primers and sequences. A.F. and T.R.B. dos Santos were supported by grants from Conselho Nacional de Desenvolvimento Científico e Tecnológico, Brazil. J.F. and K.G.B. dos Santos were supported by grants from Fundação de Amparo à Ciência e Tecnologia do Estado de Pernambuco, Brazil. The work was partially supported by the Gregor Mendel Institute of Molecular Plant Biology, Austria, and by Conselho Nacional de Desenvolvimento Científico e Tecnológico, Brazil. Development of BAC libraries was funded by the US Department of Agriculture Cooperative State Research, Education, and Extension Service National Research Initiative Plant Genome.

Open Access This article is distributed under the terms of the Creative Commons Attribution Noncommercial License which permits any noncommercial use, distribution, and reproduction in any medium, provided the original author(s) and source are credited.

\section{References}

Adam-Blondon A-F, Sévignac M, Dron M, Bannerot H (1994) A genetic map of common bean to localize specific resistance genes against anthracnose. Genome 37:915-924
Arumuganathan K, Earle ED (1991) Nuclear DNA content of some important plant species. Plant Mol Biol Rep 9:208218

Barros e Silva AE, Guerra M (2009) The meaning of DAPI bands observed after C-banding and FISH procedures. Biotech Histochem 4:1-11

Broughton WJ, Hernandez G, Blair M et al (2003) Beans (Phaseolus spp.) - model food legumes. Plant Soil 252:55-128

Cabral JS, Felix LP, Guerra M (2006) Heterochromatin diversity and its co-localization with $5 \mathrm{~S}$ and $45 \mathrm{~S}$ rDNA sites in chromosomes of four Maxillaria species (Orchidaceae). Genet Mol Biol 29:659-664

Chang SB, Yang TJ, Datema E et al (2008) FISH mapping and molecular organization of the major repetitive sequences of tomato. Chromosome Res 16:919-933

Cheng Z, Presting GG, Buell CR, Wing RA, Jiang J (2001) High-resolution pachytene chromosome mapping of bacterial artificial chromosomes anchored by genetic markers reveals the centromere location and the distribution of genetic recombination along chromosome 10 of rice. Genetics 157:1749-1757

David P, Chen NWG, Pedrosa-Harand A et al (2009) A nomadic subtelomeric disease gene cluster in common bean. Plant Physiol 151:1048-1065

David P, colas des Francs-Small C, Sévignac M, Thareau V, Macadre C, Langin T, Geffroy V (2010) Three highly similar formate dehydrogenase genes located in a cluster of NBS-LRR are differentially expressed under biotic and abiotic stresses in Phaseolus vulgaris. Theor Appl Genet. doi:10.1007/s00122-010-1293-x

Dong F, Song J, Naess SK et al (2000) Development and applications of a set of chromosome-specific cytogenetic DNA markers in potato. Theor Appl Genet 101:10011007

dos Santos GM (1986) Reviewing the chromosome nomenclature of Levan et al. Rev Bras Genet 9:741-743

Evans AM (1986) Beans. In: Simmonds NW (ed) Evolution of crop plants. Longman Scientific and Technical, Hong Kong, pp 168-172

Ferrier-Cana E, Geffroy V, Macadre C et al (2003) Characterization of expressed NBS-LRR resistance gene candidates from common bean. Theor Appl Genet 106:251-261

Fredslund J, Schauser L, Madsen LH, Sandal N, Stougaard J (2005) PriFi: using a multiple alignment of related sequences to find primers for amplification of homologs. Nucleic Acids Res 43:W516-W520

Fredslund J, Madsen LH, Hougaard BK et al (2006a) A general pipeline for the development of anchor markers for comparative genomics in plants. BMC Genomics 7:207. doi:10.1186/1471-2164-7-207

Fredslund J, Madsen LH, Hougaard BK et al (2006b) GeMprospector-online design of cross-species genetic marker candidates in legumes and grasses. Nucleic Acids Res 34:W670-W675. doi:10.1093/nar/gk1201

Freyre R, Skroch PW, Geffroy V et al (1998) Towards an integrated linkage map of common bean: 4 . Development of a core linkage map and alignment of RFLP maps. Theor Appl Genet 97:847-856

Geffroy V, Sevignac M, De Oliveira JCF et al (2000) Inheritance of partial resistance against Colletotrichum 
lindemuthianum in Phaseolus vulgaris and co-localization of quantitative trait loci with genes involved in specific resistance. Mol Plant-Microbe Interact 13:287-296

Geffroy V, Macadré C, David P et al (2009) Molecular analysis of a large subtelomeric NBS-LRR family in two representative genotypes of the major gene pools of Phaseolus vulgaris. Genetics 181:405-419

Gepts P, Beavis WD, Brummer EC et al (2005) Legumes as a model plant family. Genomics for food and feed. Report of the Cross-Legume Advances through Genomics Conference. Plant Physiol 137:1228-1235

Gepts P, Aragão FJL, Barros ED et al (2008) Genomics of Phaseolus beans, a major source of dietary protein and micronutrients in the tropics. In: Moore PH, Ming R (eds) Genomics of tropical crop plants. Springer, Berlin, pp 113-143

Gill N, Hans CS, Jackson S (2008) An overview of plant chromosome structure. Cytogenet Genome Res 120:194201

Guerra M (1993) High amount of heterochromatin in a tropical tree species: Genipa americana L. (Rutaceae). Cytologia 58:427-442

Heslop-Harrison JS, Schwarzacher T, Anamthawat-Jónsson K et al (1991) In situ hybridization with automated chromosome denaturation. Technique 3:109-115

Heslop-Harrison JS, Harrison GE, Leitch IJ (1992) Reprobing of DNA:DNA in situ hybridization preparations. TIGG 8:372-373

Houben A, Demidov D, Gernand D et al (2003) Methylation of histone $\mathrm{H} 3$ in euchromatin of plant chromosomes depends on basic nuclear DNA content. Plant J 33:967-973

Hougaard BK, Madsen LH, Sandal N et al (2008) Legume anchor markers link syntenic regions between Phaseolus vulgaris, Lotus japonicus, Medicago truncatula and Arachis. Genetics 179:2299-2312

Islam-Faridi MN, Childs KL, Klein PE et al (2002) A molecular cytogenetic map of sorghum chromosome: 1 . Fluorescence in situ hybridization analysis with mapped bacterial artificial chromosomes. Genetics 161:345-353

Jiang J, Gill BS (1996) Current status and potential of fluorescence in situ hybridization in plant genome mapping. In: Paterson AH (ed) Genome mapping in plants. RG Landes Company, Georgetown, pp 127-135

Jiang J, Gill BS (2006) Current status and the future of fluorescence in situ (FISH) in plant genome research. Genome 49:1057-1068

Kami J, Poncet V, Geffroy V, Gepts P (2006) Development of four phylogenetically-arrayed BAC libraries and sequence of the APA locus in Phaseolus vulgaris. Theor Appl Genet 112:987-998

Kim J-S, Islam-Faridi MN, Klein PE et al (2005a) Comprehensive molecular cytogenetic analysis of sorghum genome architecture: distribution of euchromatin, heterochromatin, genes and recombination in comparison to rice. Genetics 171:1963-1976

Kim J-S, Klein PE, Klein RR et al (2005b) Molecular cytogenetic maps of Sorghum linkage groups 2 and 8 . Genetics 169:955-965

Kulikova O, Gualtieri G, Geurts R et al (2001) Integration of the FISH pachytene and genetic maps of Medicago truncatula. Plant J 27:49-58
Kulikova O, Geurts R, Lamine M et al (2004) Satellite repeats in the functional centromere and pericentromeric heterochromatin of Medicago truncatula. Chromosoma 113: 276-283

Ma J, Wing RA, Bennetzen JL, Jackson SA (2007) Plant centromere organization: a dynamic structure with conserved functions. Trends Genet 23:134-139

Melotto M, Coelho MF, Pedrosa-Harand A et al (2004) The anthracnose resistance locus $\mathrm{C} 0-4$ of common bean is located on chromosome 3 and contains putative disease resistance-related genes. Theor Appl Genet 109:690-699

Moscone EA, Matzke MA, Matzke JM (1996) The use of combined FISH/GISH in conjunction with DAPI counterstaining to identify chromosomes containing transgene inserts in amphidiploid tobacco. Chromosoma 105:231-236

Moscone EA, Klein F, Lambrou M, Fuchs J, Schweizer D (1999) Quantitative karyotyping and dual-color FISH mapping of 5S and $18 \mathrm{~S}-25 \mathrm{~S}$ rDNA probes in the cultivated Phaseolus species (Leguminosae). Genome 42:1224-1233

Nagaki K, Cheng Z, Ouyang S et al (2004) Sequencing of a rice centromere uncovers active genes. Nat Genet 36:138-145

Nodari RO, Tsai SM, Gilbertson RL, Gepts P (1993) Towards an integrated linkage map of common bean: 2. Development of an RFLP-based linkage map. Theor Appl Genet 85:513-520

Pedrosa A, Sandal N, Stougaard J, Schweizer D, Bachmair A (2002) Chromosomal map of the model legume Lotus japonicus. Genetics 161:1661-1672

Pedrosa A, Vallejos CE, Bachmair A, Schweizer D (2003) Integration of common bean (Phaseolus vulgaris L.) linkage and chromosomal maps. Theor Appl Genet 106:205-212

Pedrosa-Harand A, de Almeida CCS, Mosiolek M et al (2006) Extensive ribosomal DNA amplification during Andean common bean (Phaseolus vulgaris L.) evolution. Theor Appl Genet 112:924-933

Pedrosa-Harand A, Porch T, Gepts P (2008) Standard nomenclature for common bean chromosomes and linkage groups. Annu Rep Bean Improv Coop 51:106-107

Pedrosa-Harand A, Kami J, Gepts P et al (2009) Cytogenetic mapping of common bean chromosomes reveals a less compartmentalized small-genome plant species. Chromosome Res 17:405-417

Peters SA, Datema E, Szinay D et al (2009) Solanum lycopersicum cv. Heinz 1706 chromosome 6: distribution and abundance of genes and retrotransposable elements. Plant J 58:857-869

Rozen S, Skaletsky HJ (2000) Primer3 on the WWW for general users and for biologist programmers. In: Krawetz S, Misener $\mathrm{S}$ (eds) Bioinformatics methods and protocols: methods in molecular biology. Humana, Totowa, NJ, pp 365-386

Schlueter JA, Goicoechea JL, Collura K et al (2008) BAC-end sequence analysis and a draft physical map of the common bean (Phaseolus vulgaris L.) genome. Trop Plant Biol $1: 40-48$

Shoemaker RC, Schlueter J, Doyle JJ (2006) Paleopolyploidy and gene duplication in soybean and other legumes. Curr Opin Plant Biol 9:104-109

Vallejos CE, Sakiyama NS, Chase CD (1992) A molecular marker-based linkage map of Phaseolus vulgaris L. Genetics 131:733-740

Vanhouten W, Mackenzie S (1999) Construction and characterization of a common bean bacterial artificial chromosome library. Plant Mol Biol 40:977-983 
Wanzenböck E-M, Schöfer C, Schweizer D, Bachmair A (1997) Ribosomal transcription units integrated via T-DNA transformation associate with the nucleolus and do not require upstream repeat sequences for activity in Arabidopsis thaliana. Plant J 11:1007-1016

Yan H, Jiang J (2007) Rice as a model for centromere and heterochromatin research. Chromosome Res 15:77-84

Young ND, Roe BA, Town CD, Cannon SB, Sato S, Tabta S (2005) Sequencing the genespaces of Medicago truncatula and Lotus japonicus. Plant Physiol 137:1174-1181
Zheng J, Masashi M, Uchiyama H, Morikawa H, Tanaka R (1991) Giemsa C-banding patterns in several species of Phaseolus L. and Vigna Savi, Fabaceae. Cytologia 56:459-466

Zheng JY, Nakata M, Irifune K, Tanaka R, Morikawa H (1993) Fluorescent banding pattern analysis of eight taxa of Phaseolus and Vigna in relation to their phylogenetic relationships. Theor Appl Genet 87:38-43

Zwick MS, Hanson RE, McKnight TD et al (1997) A rapid procedure for isolation of $\mathrm{C} 0 \mathrm{t}-1$ DNA from plants. Genome 40:138-142 